\title{
Total Soluble Solids from Banana: Evaluation and Optimization of Extraction Parameters
}

\author{
Giovani B. M. Carvalho • Daniel P. Silva • \\ Júlio C. Santos • Hélcio J. Izário Filho • \\ António A. Vicente • José A. Teixeira • \\ Maria das Graças A. Felipe • João B. Almeida e Silva
}

Received: 22 May 2008 / Accepted: 26 November 2008 /

Published online: 14 December 2008

(C) Humana Press 2008

\begin{abstract}
Banana, an important component in the diet of the global population, is one of the most consumed fruits in the world. This fruit is also very favorable to industry processes (e.g., fermented beverages) due to its rich content on soluble solids and minerals, with low acidity. The main objective of this work was to evaluate the influence of factors such as banana weight and extraction time during a hot aqueous extraction process on the total soluble solids content of banana. The extract is to be used by the food and beverage industries. The experiments were performed with $105 \mathrm{~mL}$ of water, considering the moisture of the ripe banana (65\%). Total sugar concentrations were obtained in a beer analyzer and the result expressed in degrees Plato $\left({ }^{\circ} \mathrm{P}\right.$, which is the weight of the extract or the sugar equivalent in $100 \mathrm{~g}$ solution at $20^{\circ} \mathrm{C}$ ), aiming at facilitating the use of these results by the beverage industries. After previous studies of characterization of the fruit and of ripening performance, a $2^{2}$ full-factorial star design was carried out, and a model was developed to describe the behavior of the dependent variable (total soluble solids) as a function of the factors (banana weight and extraction time), indicating as optimum conditions for extraction $38.5 \mathrm{~g}$ of banana at $39.7 \mathrm{~min}$.
\end{abstract}

Keywords Banana $\cdot$ Soluble sugars $\cdot$ Extraction process $\cdot$ Experimental design $\cdot$ Response surface

\section{Introduction}

Nowadays, biotechnology includes a wide range of diverse technologies that may be applied in each of the different food and agriculture sectors. In this context, several studies

G. B. M. Carvalho · J. C. Santos · H. J. Izário Filho • M. G. A. Felipe • J. B. Almeida e Silva Biotechnology Department, Engineering School of Lorena, University of São Paulo, Campus I, P.O. Box116, 12602-810 Lorena, SP, Brazil

G. B. M. Carvalho $\cdot$ D. P. Silva $(\bowtie) \cdot$ A. A. Vicente $\cdot$ J. A. Teixeira IBB - Institute for Biotechnology and Bioengineering, Centre of Biological Engineering, University of Minho, Campus de Gualtar, Braga 4710-057, Portugal e-mail: silvadp@deb.uminho.pt 
to obtain foods or beverages from fruits, such as orange, grape, or apple, have been carried out. With the development of the processing industries of different fruits and the increase in production of processed fruit products (e.g., as chips, flours, dried pulps and jam, and beverages), potential perspectives of control and/or treatment and extraction processes of its compounds are in constant increase $[1,2]$.

Banana, one of the most significant foodstuffs in the world, is one of the oldest fruits known to mankind as an important energy-producing food and is also a good source of mineral salts and vitamins [3]. Furthermore, sensorial attributes of the banana, as flavor, taste, texture, and color, are significantly influenced by its chemical composition, especially by acids, sugars, and phenolic compounds. Studies have revealed physicochemical, nutritional, and sensorial differences according to the region of origin of the bananas $[4,5]$.

Banana production in tropical and subtropical regions is an important financial resource and is the main economic activity for many countries, as well as an essential component in the diet of the global population. According to Food and Agriculture Organization of the United Nations - FAO [6], among the major producers of banana worldwide, in 2006, India was the first with $11.7 \times 10^{6}$ tonnes, which corresponded to $16.5 \%$ of the world production, and Brazil was the second with $7.1 \times 10^{6}$ tonnes (approximately $10 \%$ of the world production).

In the last decades, experimental design and other related statistical methods have been used to systematically examine different types of problems that arise within the fields of, e.g., research, development, and production [7, 8]. These designs include blocking and factorial experiments for determining the path of steepest ascent in order to identify the effect of individual factors and to approach the neighborhood of the optimum response [9].

In the present work, the response surface methodology was used to verify the influence of factors as wet weight of banana and time on the total soluble solids extraction from banana during an aqueous extraction process under heating. This work was preceded by preliminary studies of characterization of the fruit and of its ripening performance.

\section{Materials and Methods}

\section{Raw Material}

Good quality green banana fruits of the variety Prata (Musa spp.) were provided by EMATER (Empresa de Assistência Técnica e Extensão Rural do Estado de Minas Gerais) in Cristina, state of Minas Gerais, Brazil. This variety was chosen by considering the great production and availability in Brazil, which results in accessible price at markets. They were sanitized with running potable water, manually peeled, cut in the form of discs (thickness, $0.5 \mathrm{~cm}$ ), and triturated in a blender before use.

Initially, the fruits were characterized and evaluated at three different times throughout their ripening. This characterization was performed using a scale representing ripening stages for Prata banana classified by the color of banana peel, ranging from 1 to 8 , which was developed by Loeseck [10], as follows: green (1), traces of yellow (2), more green than yellow (3), more yellow than green (4), yellow with green endings (5), completely yellow (6), yellow with slight brown specks (7), and yellow with more brown specks (8). Thus, for each stage evaluated in this work (stages: 3-more green than yellow, 6-completely yellow, and 8-yellow with more brown specks), samples were chemically analyzed for their contents of moisture, starch, and soluble sugars (reducing, non-reducing, and total sugars), expressed as gram of carbohydrates in $100 \mathrm{~g}$ of wet banana pulp, as well as, 
concentrations of $\mathrm{Ca}, \mathrm{Mg}, \mathrm{K}, \mathrm{Na}, \mathrm{Al}$, and $\mathrm{Fe}$. Stages of maturation of the fruit were controlled in laboratory at room temperature $\left(20-25^{\circ} \mathrm{C}\right)$.

Initial Characterization: Starch, Soluble Carbohydrates, and Mineral Salts

The starch quantification in the banana pulps was determined according to the Instituto Adolfo Lutz-IAL [11] after some modifications. In many cases, starch quantification is not made directly; it is calculated after its total hydrolysis to glucose. Thus, samples were initially defatted with diethyl ether $(5 \mathrm{~g}$ banana pulp treated with three volumes of $20 \mathrm{~mL}$ solvent), and the soluble sugars were removed with $70 \%$ ethanol at $83-87^{\circ} \mathrm{C} / 1 \mathrm{~h}(100 \mathrm{~mL}$ ethanol with $0.5 \mathrm{~g}$ calcium carbonate). After natural cooling and rest for $15 \mathrm{~h}$, the volume was completed to $250 \mathrm{~mL}$ with ethanol $95 \%$. In this stage, sediment (residue) and supernatant (liquid) were separated for determination of the starch concentration and soluble carbohydrates, respectively.

After washing the residue with $50 \mathrm{~mL}$ ethanol $70 \%$, the residue, together with the filter paper, was transferred to an Erlenmeyer with $150 \mathrm{~mL}$ of deionized water. Four drops of sodium hydroxide solution $10 \%$ was added to mixture, and it was put at autoclave for $1.0 \mathrm{~atm} / 121{ }^{\circ} \mathrm{C} / 1.0 \mathrm{~h}$. The starch was hydrolyzed adding $5 \mathrm{~mL}$ of hydrochloric acid in the resultant solution and treating again at autoclave for $1.0 \mathrm{~atm} / 121{ }^{\circ} \mathrm{C} / 0.5 \mathrm{~h}$. The resultant solution was neutralized with sodium hydroxide $10 \%$, and the volume was completed to $250 \mathrm{~mL}$ with deionized water. Starch levels (grams per $100 \mathrm{~g}$ fresh pulp) were determined by the correlation with the values of reduced sugars in glucose obtained by SomogyNelson method $[12,13]$. Using the supernatant obtained early in the extraction process and after evaporation of the liquid phase, the resultant residue was mixed with solution of neutral acetate of lead until complete dissolution $(3.8 \mathrm{~mL})$. The final volume was completed to $500 \mathrm{~mL}$ (deionized water), and sodium sulfate was added (dry solids) until total precipitation of the lead in excess. After filtration, samples of this solution were used to quantification of soluble reduction sugars in the pulp (Somogy-Nelson method) and total sugars by hydrolysis procedure. Non-reduction sugars were obtained by the difference between the total sugars and the reduction sugars.

Quantification of $\mathrm{Ca}, \mathrm{Mg}, \mathrm{K}, \mathrm{Na}, \mathrm{Al}$, and $\mathrm{Fe}$ were obtained in the three ripening stages of the banana pulps evaluated in this work. These elements were determined by atomic absorption spectrometry (model Analyst 800, PerkinElmer) after partial digestion in acid media $\left(\mathrm{HCl} / \mathrm{HNO}_{3}\right)$ and total digestion of organic matter by peroxide (decomposition of the sugars and organic materials), followed by analytical determination.

Extraction Experiments of Total Soluble Solids from Banana

Extractions were made by immersing different amounts of banana paste in deionized water and heating in a thermo-regulated device at $84^{\circ} \mathrm{C}$ for selected periods of time (Table 1). In all cases,

Table 1 Experimental range and levels of the independent variables according to the $2^{2}$ full-factorial central composite design.

\begin{tabular}{|c|c|c|c|c|c|c|}
\hline \multirow[t]{2}{*}{ Independent variable } & \multirow[t]{2}{*}{ Symbol } & \multicolumn{5}{|c|}{ Range and levels } \\
\hline & & $-2^{1 / 2}$ & -1 & 0 & +1 & $+2^{1 / 2}$ \\
\hline Wet weight (g) & $X_{1}$ & 13.3 & 17.0 & 26.0 & 35.0 & 38.7 \\
\hline Extraction time (min) & $X_{2}$ & 23.8 & 30.0 & 45.0 & 60.0 & 66.2 \\
\hline
\end{tabular}


the moisture of the banana was taken into account. After the extraction procedure, the juice was centrifuged at $1,400 \times \mathrm{g}$ for $15 \mathrm{~min}$, and the supernatant was used to determine the total soluble solids at $20{ }^{\circ} \mathrm{C}$ (Beer Analyzer 2, Anton-Paar, Austria), with the results expressed in degrees Plato $\left({ }^{\circ} \mathrm{P}\right)[14]$, which is the weight of the extract or the sugar equivalent present in $100 \mathrm{~g}$ of the solution (reflecting the soluble sugars concentration after extraction).

\section{Experimental Design and Statistical Analysis}

A $2^{2}$ full-factorial central composite design with five coded levels leading to 12 sets of experiments was performed. For statistical calculation, the variables were coded according to Eq. 1, where $x i$ is the independent variable coded value, $X_{i}$ is the independent variable real value, $X_{0}$ is the independent variable real value on the center point, and $\Delta X_{i}$ is the step change value. The range and the levels of the variables investigated in this study are given in Table 1 .

$$
x i=\left(X_{i}-X_{0}\right) / \Delta X_{i}
$$

Total soluble solids concentration obtained from banana was taken as the dependent variables or responses of the design experiments. The quadratic model for predicting the optimal point was expressed according to Eq. 2, where $Y$ represents the response variable, $b_{0}$ is the interception coefficient, $b_{1}$ and $b_{2}$ are the linear terms, $b_{11}$ and $b_{22}$ are the quadratic terms, and $X_{1}$ and $X_{2}$ represent the variables studied.

$$
Y=b_{0}+b_{1} X_{1}+b_{2} X_{2}+b_{12} X_{1} X_{2}+b_{11} X_{1}^{2}+b_{22} X_{2}^{2}
$$

The Design expert (version 5.0) and Statistica (version 5.0) software were used for regression and graphical analyses of the data obtained. The statistical significance of the regression coefficients was determined by Student's $t$ test, the second-order model equation was determined by Fischer's test, and the proportion of variance explained by the model obtained was given by the multiple coefficient of determination, $R^{2}$.

\section{Results and Discussion}

Initial Raw Material Characterization and Ripening Performance Studies

The results obtained in the initial raw material characterization and ripening performance are shown in Fig. 1 and Table 2. During natural ripening, evaluated between stages 3 (more

Fig. 1 Levels of starch (gray bars) and total soluble sugars (black bars) in Prata banana during ripening stages, scale according to Loeseck [10]: 1 green, 2 traces of yellow, 3 more green than yellow, 4 more yellow than green, 5 yellow with green endings, 6 completely yellow, 7 yellow with slight brow specks, 8 yellow with more brown specks
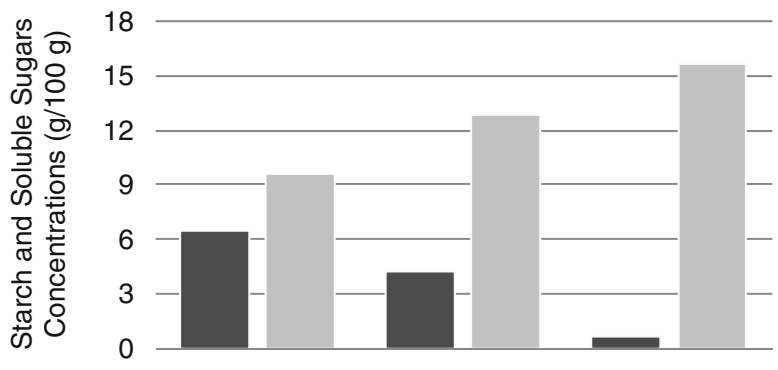

3
8

Ripening Stages of Prata Banana 
Table 2 Levels of moisture (percent $w / w$ ) and reduction, non-reduction, and total sugars (percent $w / w$ ) obtained in different ripening stages.

\begin{tabular}{lcrrr}
\hline \multirow{2}{*}{ Ripening stages } & Moisture $^{\mathrm{a}}(\% w / w)$ & \multicolumn{2}{l}{ Sugars $^{\mathrm{a}}(\% w / w)$} & \\
\cline { 3 - 5 } & & \multicolumn{1}{l}{ Reduction } & Non-reduction & Total \\
\hline (3) More green than yellow & $62.13 \pm 0.12$ & $7.39 \pm 0.34$ & $2.20 \pm 0.22$ & $9.59 \pm 0.56$ \\
(6) Completely yellow (ripe fruit) & $63.00 \pm 0.08$ & $8.36 \pm 0.37$ & $4.52 \pm 0.54$ & $12.88 \pm 0.87$ \\
(8) Yellow with more brown specks & $65.12 \pm 0.16$ & $12.45 \pm 0.44$ & $3.20 \pm 0.23$ & $15.65 \pm 0.66$ \\
\hline
\end{tabular}

${ }^{\mathrm{a}}$ Experiments and measurements made in triplicates

green than yellow) and 8 (yellow with more brown specks) at approximately 25 days of storage, the starch concentration decreased significantly from $6.46 \% w / w$ to $0.48 \% w / w$, while the total soluble sugars increased from 9.59 to $15.65 \% w / w$, respectively.

These results are similar to those reported by Adão and Glória [15], Fernandes et al. [16], and Loeseck [10]. Fernandes et al. [16], also working with banana of the variety Prata, observed a decrease in the starch concentration from $7.80 \% w / w$ to $0.63 \% w / w$, and Adão and Glória [15] observed an increased in the total soluble sugars concentration from 1.26 to $14.8 \% \mathrm{w} / \mathrm{w}$.

According to Zhang et al. [17], the average starch content drops from $70 \%$ to $80 \%$ in the preclimacteric (prior to starch breakdown) period to less than $1 \%$ at the end of the climacteric period, while sugars accumulate to more than $10 \%$ of the fresh weight of the fruit. In this work, we found $4.28 \% \mathrm{w} / \mathrm{w}$ of starch concentration in stage 6 (completely yellow). These results are close to starch levels found by Mota et al. [18] for ripe bananas, between 2.5\% and 5.2\% w/w.

According to Adão et al. [15], Prata is one of the most consumed banana varieties in Brazil. Working with carbohydrate changes during ripening, these authors detected three types of soluble sugars in Prata banana: fructose, glucose, and sucrose. Table 2 shows that reducing sugars (as glucose and fructose) levels were predominant during all the three stages evaluated in our work. These results are in agreement with those previously obtained by Fernandes [16]. However, according to these authors, sucrose (representing nonreduction sugars) levels are higher than glucose and fructose levels in early stages (e.g., green and traces of yellow stages, stages 1 and 2), followed by a decrease during the subsequent stages of Prata banana ripening.

There was an increase in water content of the banana pulp from $62.13 \% \mathrm{w} / \mathrm{w}$ to $65.12 \%$ $w / w$ during the ripening stages evaluated (Table 2). According to Loeseck [10] and Fernandes

Table 3 Performance obtained of mineral salts concentration during ripening stages in Prata banana values represented in oxide element.

\begin{tabular}{lccr}
\hline Chemical element (in its oxide compound) & \multicolumn{2}{l}{ Mineral salts concentration (\%) } \\
\cline { 2 - 4 } & $\begin{array}{l}\text { Stage 3 } \\
\text { (little ripe fruit) }\end{array}$ & $\begin{array}{l}\text { Stage 6 } \\
\text { (ripe fruit) }\end{array}$ & $\begin{array}{l}\text { Stage 8 } \\
\text { (more ripe fruit) }\end{array}$ \\
\hline Iron $\left(\mathrm{Fe}_{2} \mathrm{O}_{3}\right)$ & 1.590 & 1.230 & 0.737 \\
Calcium $(\mathrm{CaO})$ & 0.120 & 0.092 & 0.081 \\
Sodium $\left(\mathrm{Na}_{2} \mathrm{O}\right)$ & 0.338 & 0.213 & 0.121 \\
Potassium $\left(\mathrm{K}_{2} \mathrm{O}\right)$ & 42.952 & 42.613 & 42.327 \\
Magnesium $(\mathrm{MgO})$ & 0.104 & 0.095 & 0.079 \\
Aluminum $\left(\mathrm{Al}_{2} \mathrm{O}_{3}\right)$ & 0.382 & 0.217 & 0.100 \\
\hline
\end{tabular}


Table 4 Experimental design and results according to the $2^{2}$ full-factorial central composite design.

\begin{tabular}{|c|c|c|c|c|c|}
\hline \multirow[t]{3}{*}{ Runs } & \multicolumn{4}{|c|}{ Independent variables } & \multirow[t]{3}{*}{ Dependent variable (response factor) } \\
\hline & \multicolumn{2}{|l|}{ Real levels } & \multicolumn{2}{|c|}{ Coded levels } & \\
\hline & Weight (g) & Time (min) & Weight & Time & \\
\hline 1 & 17.0 & 30.0 & -1 & -1 & 4.12 \\
\hline 2 & 35.0 & 30.0 & +1 & -1 & 6.68 \\
\hline 3 & 17.0 & 60.0 & -1 & +1 & 4.82 \\
\hline 4 & 35.0 & 60.0 & +1 & +1 & 6.63 \\
\hline 5 & 26.0 & 45.0 & 0 & 0 & 5.54 \\
\hline 6 & 26.0 & 45.0 & 0 & 0 & 5.57 \\
\hline 7 & 26.0 & 45.0 & 0 & 0 & 5.07 \\
\hline 8 & 26.0 & 45.0 & 0 & 0 & 5.55 \\
\hline 9 & 13.3 & 45.0 & $-2^{1 / 2}$ & 0 & 3.53 \\
\hline 10 & 38.7 & 45.0 & $+2^{1 / 2}$ & 0 & 7.51 \\
\hline 11 & 26.0 & 23.8 & 0 & $-2^{1 / 2}$ & 5.45 \\
\hline 12 & 26.0 & 66.2 & 0 & $+2^{1 / 2}$ & 3.53 \\
\hline
\end{tabular}

${ }^{\mathrm{a}}$ Extraction of total soluble solids from banana (EB)

et al. [16], the increase in moisture during ripening is due to carbohydrates utilized in respiration and osmotic transfer from the peel to the pulp. Adão and Glória [15] explained that this happens as a marked difference in osmotic pressure between peel and pulp develops during ripening because sugar content increases more rapidly in the pulp than in the peel.

This increase in moisture during ripening stages can explain the changes obtained in mineral salts content (such as calcium, potassium, sodium, aluminum, iron, and magnesium) of the banana used in this work. During the ripening stages, there was a decrease of the values of their concentrations (in terms of their oxide compounds), presented in Table 3.

\section{Experimental Design: Total Soluble Solids Extraction from Prata Banana}

The effects of variables such as extraction time [minute] and wet weight of banana [gram] on the extraction performance of total soluble solids [ $\left.{ }^{\circ} \mathrm{P}\right]$ from Prata banana were simultaneously investigated employing a full-factorial design consisting of $2^{2}$ trials plus a star configuration $\left(\alpha= \pm 2^{1 / 2}\right)$ and four replicates at the center point. In earlier published work [8], different conditions of extraction time [minute] and temperature [degree Celsius]

Table 5 Estimated effects, standard errors, Student's $t$ test, and significance levels for extraction of total soluble solids from Prata banana (EB) using the $2^{2}$ full-factorial star design.

\begin{tabular}{lcccc}
\hline Effects & Estimated & Standard errors & $t$ value & Probability \\
\hline Average & 5.5790 & 0.0937 & 59.5273 & $0.0000^{\mathrm{a}}$ \\
WW $^{\mathrm{b}}$ & 2.4996 & 0.1711 & 14.6083 & $0.0007^{\mathrm{a}}$ \\
ET $^{\mathrm{c}}$ & -0.5163 & 0.1711 & -3.0175 & 0.0569 \\
ET $^{2}$ & -0.7370 & 0.1874 & -3.9318 & $0.0293^{\mathrm{a}}$ \\
\hline
\end{tabular}

\footnotetext{
${ }^{\text {a }}$ Significant level of the variables and their interactions at $95 \%$ (5\% probability level)

${ }^{\mathrm{b}}$ WW wet weight $\left(X_{1}\right)$

${ }^{\mathrm{c}}$ ET extraction time $\left(X_{2}\right)$
} 
Table 6 Regression coefficients, standard errors, Student's $t$ test, and significance levels for the model representing the extraction of total soluble solids from Prata banana (EB).

\begin{tabular}{llcccc}
\hline Independent variables & Parameters & Coefficients & Standard errors & $t$ value & Probability \\
\hline Intercept & Constant & 5.5790 & 0.0937 & 59.5273 & $0.0000^{\mathrm{a}}$ \\
$\mathrm{WW}^{\mathrm{b}}$ & $X_{1}$ & 1.2498 & 0.0856 & 14.6083 & $0.0007^{\mathrm{a}}$ \\
$\mathrm{ET}^{\mathrm{c}}$ & $X_{2}$ & -0.2582 & 0.0856 & -3.0175 & 0.0569 \\
$\mathrm{ET}^{2}$ & $X_{2}{ }^{2}$ & -0.3685 & 0.0937 & -3.9318 & $0.0293^{\mathrm{a}}$ \\
\hline
\end{tabular}

$R^{2}=0.83$ and adjusted $R^{2}=0.77$

${ }^{\text {a }}$ Significant level of the variables and their interactions at $95 \%$ (5\% probability level)

${ }^{\mathrm{b}}$ WW wet weight $\left(X_{1}\right)$

${ }^{\mathrm{c}}$ ET extraction time $\left(X_{2}\right)$

for hot aqueous extraction of banana juice showed significant effects on the extraction of total soluble solids [degree Brix], as well as on organoleptic characteristics (odor and taste) of the final product. Based in these results, the extraction temperature used in the present work was fixed at $84{ }^{\circ} \mathrm{C}$.

The design matrix with the real and coded levels of wet weight and extraction time and the amounts of extracted sugars is shown in Table 4. The highest extraction of total soluble solids from banana (EB) occurred when the real levels of the weight and time variables were $38.7 \mathrm{~g}$ and $45.0 \mathrm{~min}$, respectively. On the other hand, the lowest sugars extraction occurred when the real levels of the weight and time variables were $13.3 \mathrm{~g}$ and $45.0 \mathrm{~min}$ and also $26.0 \mathrm{~g}$ and $23.8 \mathrm{~min}$, respectively.

The estimated effects, standard errors, and Student's $t$ test for the $2^{2}$ full-factorial star design are shown in Table 5. According to the Student's $t$ test shown, the main effect (or linear) of the factor wet weight of banana (WW) and the quadratic effect of the factor extraction time $\left(\mathrm{ET}^{2}\right)$ significantly influenced the response function (sugars extraction from banana, EB) at a 5\% probability level. For instance, increasing the wet weight of banana in the extraction process from 26.0 to $38.7 \mathrm{~g}$ (at the time of $45 \mathrm{~min}$ ) increased from 5.55 to $7.51{ }^{\circ} \mathrm{P}$ the extracted total soluble solids.

Regression analysis was performed to fit the response function with the experimental data (Table 6). Although only the main effect of wet weight $\left(X_{1}\right)$ and the quadratic effect of time $\left(X_{2}^{2}\right)$ were significant at a $5 \%$ probability level, in order to minimize the error determination and due to the situation of existent hierarchy, the main effect of the time factor $\left(X_{2}\right)$ was also kept in the model. Thus, the model expressed by Eq. 3, where the

Table 7 Analysis of variance (ANOVA) for the model regression representing extraction of total soluble solids from Prata banana (EB).

\begin{tabular}{lccccc}
\hline Sources of variations & Sum of squares & Degrees of freedom & Mean square & $F$ value & Probability \\
\hline Model & 13.9349 & 3 & 4.6450 & 5.3900 & $0.0127^{\mathrm{a}}$ \\
Lack of fit & 2.5905 & 5 & 0.5181 & 8.8477 & 0.0513 \\
Pure error & 0.1757 & 3 & 0.0586 & - & - \\
Residual & 2.7662 & 8 & 0.3458 & - & - \\
Total & 16.7011 & 11 & - & - & - \\
\hline
\end{tabular}

$R^{2}=0.83$ and adjusted $\mathrm{R}^{2}=0.77$; medium absolute error $=0.3253$; standard error $=0.5881$

${ }^{\text {a }}$ Significant level of the variables and their interactions at $95 \%$ (5\% probability level) 
Fig. 2 Response surface described by the model $Y$, which represents the extraction of total soluble solids from Prata banana $(E B)$

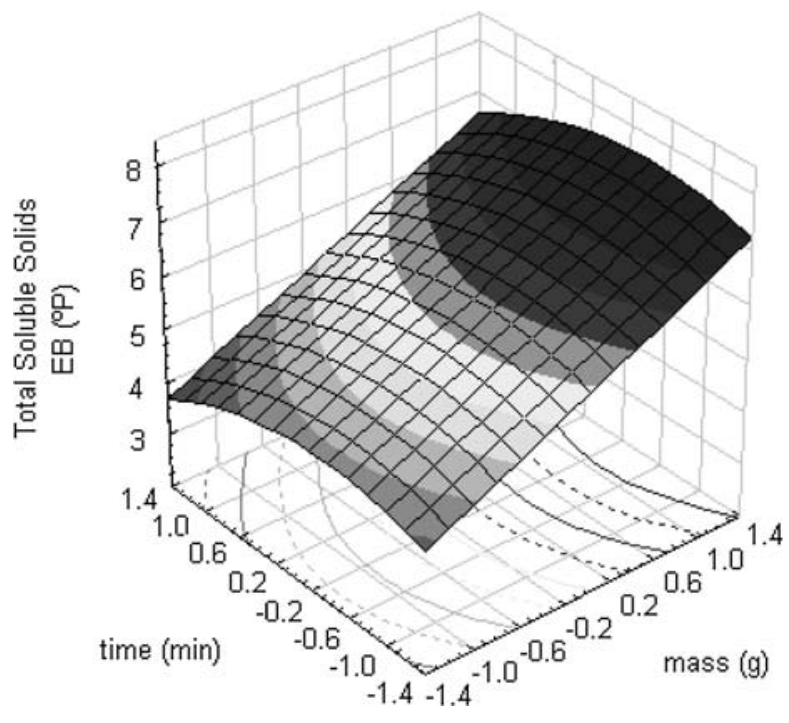

variables take their coded values, represents the extraction of total soluble solids $(Y)$ as a function of the variables: wet weight $\left(X_{1}\right)$ and extraction time $\left(X_{2}\right)$.

$$
Y=5.5790+1.2498 X_{1}-0.2582 X_{2}-0.3685 X_{2}^{2}
$$

The statistical significance of the second-order model equation (Table 7) was evaluated by the $F$-test analysis of variance (ANOVA), which revealed that this regression is statistically significant $(P<0.05)$ at a $95 \%$ of confidence level. The model did not show significant lack-of-fit, and the determination coefficient $\left(R^{2}\right)$ value indicated that the model allows explaining $83.4 \%$ of the variability in the responses. The response surface described by the model equation $(Y)$ is represented in Fig. 2.

According to these results, the optimum point for extraction of total soluble solids of Prata banana was found in the time established in the level -0.350 (equivalent to $39.75 \mathrm{~min}$ ) and in the higher level of wet weight evaluated +1.4142 (equivalent to $38.7 \mathrm{~g}$ ). In these conditions, the model presents a predicted response of total soluble solids of $7.40^{\circ} \mathrm{P}$. In previous studies, it was observed that for higher wet weight values than that shown at the level 1.4142, the

Table 8 Extraction processes conducted under optimized conditions (laboratory scale $105 \mathrm{~mL}$ ) and on experimental conditions similar to the first assay of the factorial design (pilot scale $105 \mathrm{~L}$ ).

Experimental conditions for extraction of total soluble solids from Prata banana (EB)

Laboratory scale, $105 \mathrm{~mL}-100 \mathrm{rpm} / 84{ }^{\circ} \mathrm{C}$; optimized Pilot scale, $105 \mathrm{~L}-100 \mathrm{rpm} / 84{ }^{\circ} \mathrm{C}$; experimental condition, $38.70 \mathrm{~g} / 39.75 \mathrm{~min}$ condition, $17 \mathrm{~kg} / 30 \mathrm{~min}$

\begin{tabular}{lrrrr}
\hline Predicted response $^{\mathrm{a}}$ & Observed value $^{\mathrm{b}}$ & & Predicted response $^{\mathrm{a}}$ & Observed value \\
\hline $7.39 \pm 0.37\left({ }^{\circ} \mathrm{P}\right)$ & $7.69 \pm 0.65\left({ }^{\circ} \mathrm{P}\right)$ & & $4.22 \pm 0.21\left({ }^{\circ} \mathrm{P}\right)$ & $4.22\left({ }^{\circ} \mathrm{P}\right)$ \\
\hline
\end{tabular}

\footnotetext{
${ }^{\text {a }}$ Predicted response of total soluble solids showed by empirical model

${ }^{\mathrm{b}}$ Experiments and measurements made in triplicates
} 
resultant solution (banana juice) presents unviable characteristics from the practical point of view for further application as, e.g., occurrence of fermentation.

In order to validate the empirical mathematical model representative of the response function (Eq. 3), as well as the response surface itself (Fig. 2), extraction processes were conducted under optimized conditions. In addition, a scale-up procedure was also conducted following the same conditions of experiment 1 shown in the initial experimental design. For this, the runs of the scaled-up process were carried out in a stainless steel tank (105 L volume) with controlled conditions of temperature and agitation.

All these results are shown in Table 8, indicating that the model fitted the experimental data and thus described the region studied and that the results obtained at a pilot scale are in agreement with those previously obtained at a laboratory scale. The next step should be to evaluate and explore potential applications in different biotechnological processes, particularly in the beverage or other food processing industries.

\section{Conclusions}

This work started with the evaluation of the maturation stage of Prata bananas; maturation involved an increase in moisture and soluble sugar content and, at the same time, a decrease in starch content. The results obtained with the response surface methodology were adjusted by a quadratic model $\left(Y=5.58+1.25 X_{1}-0.26 X_{2}-0.37 X_{2}^{2}\right)$ in order to obtain the optimal extraction of the total soluble solids The values that optimized the extraction of total soluble solids $(Y)$ were $38.5 \mathrm{~g}$ banana weight $\left(X_{1}\right)$ and $39.7 \mathrm{~min}\left(X_{2}\right)$ of extraction time. These values were compared with the model predicted values indicating that the model fitted the experimental data and thus described the region studied. Furthermore, the assays performed on a scaled-up equipment demonstrated the efficiency and the possibility of industrial implementation of the process studied in this work.

Acknowledgments The authors would like to thank the Fundação de Amparo à Pesquisa do Estado de São Paulo (Fapesp) and Coordenação para Aperfeiçoamento do Ensino Superior (CAPES), Brazil, Fundação para a Ciência e Tecnologia (FCT) and Gabinete de Relações Internacionais da Ciência e do Ensino Superior (GRICES), Portugal, for their financial support in this work.

\section{References}

1. Serrat, M., Bermúdez, R. C., \& Villa, T. G. (2004). Applied Biochemistry and Biotechnology, 17(1), 4964. doi:10.1385/ABAB:117:1:49.

2. Guémas, Y., Boujtita, M., \& Murr, N. L. (2000). Applied Biochemistry and Biotechnology, 89(2-3), 171182. doi:10.1385/ABAB:89:2-3:171.

3. Harish, S., Kavino, M., Kumar, N., Saravanakumar, D., Soorianathasundaram, K., \& Samiyappan, R. (2008). Applied Soil Ecology, 39, 187-200. doi:10.1016/j.apsoil.2007.12.006.

4. Cano, M. P., Ancos, B., Matallana, M. C., Camara, M., Reglero, G., \& Tabera, J. (1997). Food Chemistry, 59, 411-419. doi:10.1016/S0308-8146(96)00285-3.

5. Hardisson, A., Rubio, C., Baez, A., Martin, M., Alvarez, R., \& Diaz, E. (2001). Food Chemistry, 73, 153-161. doi:10.1016/S0308-8146(00)00252-1.

6. FAO, Food and Agriculture Organization of the United Nations.(2008) FAOSTAT statistics database http://faostat.fao.org/site/567/DesktopDefault.aspx?PageID=567 (last updated 11 May 2008).

7. Lundstedt, T., Seifert, E., Abramo, L., Thelin, B., Nystrom, A., Pettersena, J., et al. (1998). Chemometrics and Intelligent Laboratory Systems, 42, 3-40. doi:10.1016/S0169-7439(98)00065-3.

8. Lee, K. M., \& Gilmore, D. F. (2006). Applied Biochemistry and Biotechnology, 135(2), 101-116. doi:10.1385/ABAB:135:2:101. 
9. Box, G. E. P., Hunter, W., \& Hunter, J. S. (1978). Statistics for experimenters. New York: Wiley.

10. Loeseck, H. W. (1950). Chemical changes during ripening. Bananas-chemistry, physiology and technology, v.4. New York: Interscience.

11. IAL - Normas Analíticas do Instituto Adolfo Lutz (1985). Métodos Químicos e Físicos para Análise de Alimentos v. $13^{a}$ ed. São Paulo: Instituto Adolfo Lutz.

12. Somogy, M. A. (1945). The Journal of Biological Chemistry, 160(1), 601-668.

13. Nelson, N. A. (1944). The Journal of Biological Chemistry, 153, 375-380.

14. Silva, D. P., Brányik, T., Dragone, G., Vicente, A. A., Teixeira, J. A., \& Almeida e Silva, J. B. (2008). Chem. Pap, 62(1), 34-41. doi:10.2478/s11696-007-0076-6.

15. Adão, R. C., \& Glória, M. B. A. (2005). Food Chemistry, 90, 705-711. doi:10.1016/j.food chem.2004.05.020.

16. Fernandes, K. M., Carvalho, V. D., \& Cal-Vidal, J. (1979). Journal of Food Science, 44(4), 1254-1255. doi:10.1111/j.1365-2621.1979.tb03493.x.

17. Zhang, P., Whistler, R. L., BeMiller, J. N., \& Hamaker, B. R. (2005). Carbohydrate Polymers, 59, 443458. doi:10.1016/j.carbpol.2004.10.014.

18. Mota, R. V., Lajolo, F. M., \& Cordenunsi, B. R. (1997). Ciência Tecnol de Alimentes, 17(2), 94-97. 